\title{
残留応力除去に関する二. 三の実験*
}

\author{
高沖亮** \\ SOME EXPERIMENTS ON RESIDUAL STRESS RELIEVING
}

Akira Takaoki

Synopsis:

In large forgings, such as turbine rotor, it is important operation to relief the residual stress. Therefore some experiments on stress relieving were studied by the Sachs's boring-out method. The specimens (70 mm diameter, $210 \mathrm{~mm}$ long) were quenched in water from just below Ac transformation temperature, and then reheated at various temperatures and during different hours $\left(100 \sim 600^{\circ} \mathrm{C}, 1 \sim 90 \mathrm{~h}\right)$. The results obtained were as follows;

(1) Residual stress relieving depended mainly on the heating temperature, and the curve of stress relief showed linearity for it.

(2) Heating for long time had scarcely affected on the stress relieving.

(3) Variation of hardness at the surface of specimens by tempering showed approximately the condition of stress relieving.

\section{I. 緒言}

大型鏺銅材，とくにタービンローター等の残留它力除 去は大切な作業の一つである・てれらの残留応力には熱 処理による応力の外譏栊加工雨等があり, 除去に当つて は銅材を一样に加熱する方法を調質後行うのか通例であ る.

本報告は変態の影響を全く受けない泠却応力を70 棒に殘留せしめ，それを各種の温度および時間で一様に 加熱した時の応力除去状沿を調べたものである.すでに H. Büler, E. Scheil, S. Fuchs その他により焼入れ 戻しによつて変態が加味されたものの応力測定は若干行 われているリ．しかし純粋な冾却庍力の除去状況につい て，また時間の影響についての報告は見当らないようで ある. 測定には Sachs の方法を用いたが，てれは変態 を考感に入れた計算にす利用するためのものである2，

\section{II. 試料および実験要領}

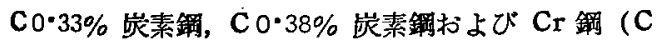
$\left.0.87 \%, C_{r} 1 \cdot 70 \%\right)$ からそれぞれ直径 $70 \mathrm{~mm}$ 長さ 210 血mの試料を多数製作した. Table 1 にその熱娃理要 領を示すどとく，加熱時間を一定として温度の影響およ び加熱温度を一定として時間の影響等をしらべた．Fig. 1 は温度測定要領を示し, 温度および時間はA点で測定 した。試料中心温度 (B点) が試料表面温度 (A点) と 一致する時間曲線を営に図示のでとくなるよう電流調整 を行つた．なお，C点とA点とでは温度差ははとんどな かつた.
Table 1. Specimen and its heat treatment.

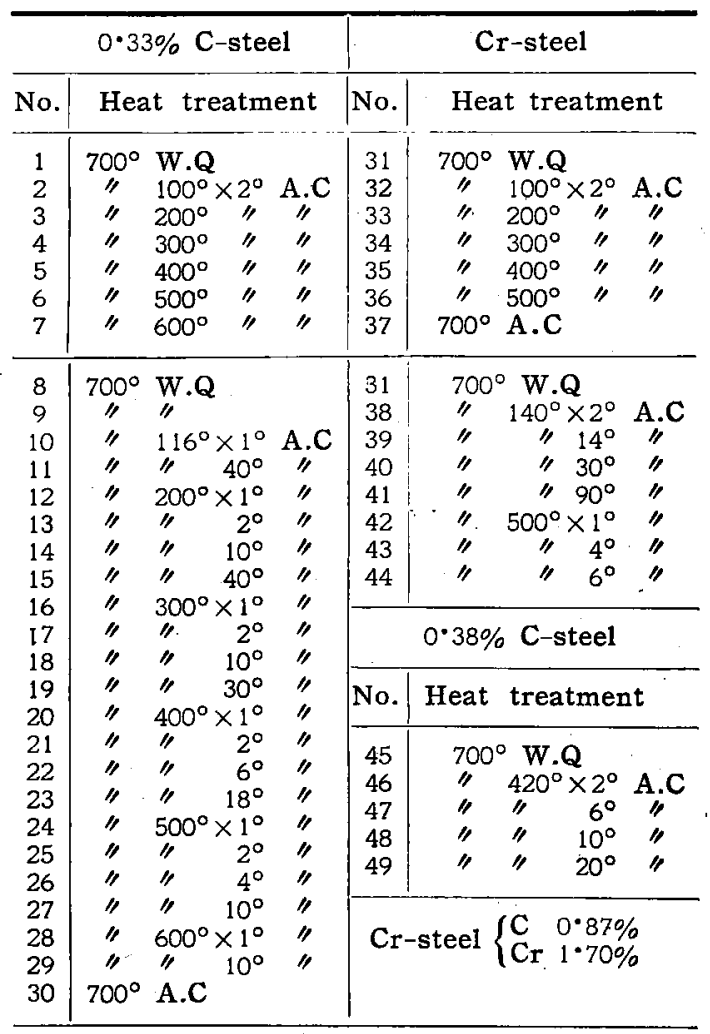

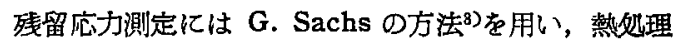

* 本会第 42 回誂演大会にて発表

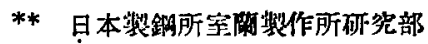




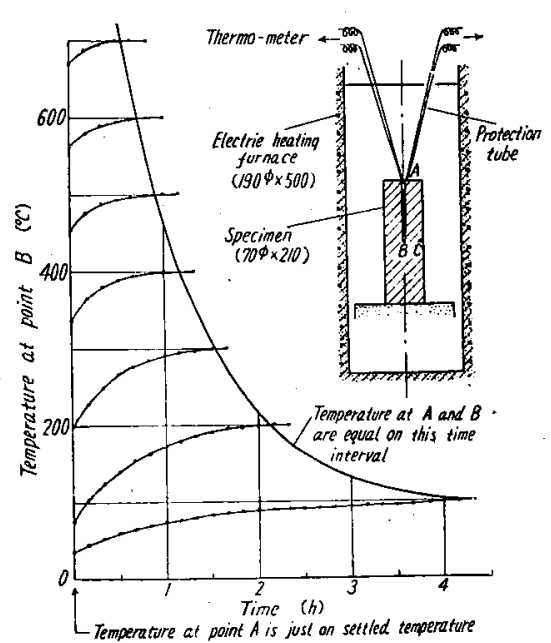

Fig. 1. Coincidental time curve of temperature at center and surface of the specimen which is on heating.

後試料は全面研暨仕上を行い，柾測定にはストレーンッ 一ターおよぴ、イクロダーターを併用しだ．驾孔に当つ ては水冷を用い，歪測定特はなるべく試料と室温とを一

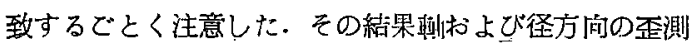
定值のバラツキは少なく非学に滑かな曲線がえられた。

\section{III. 実 験 結 果}

1. 各整温度で一定時間保持した場合

$700^{\circ} \mathrm{C}$ W.Q 試料を $100 \sim 600^{\circ} \mathrm{C}$ で垎.及 2 時間保持し た時の残留応力分枋を Fig. 2 亿示す. 実測点は $r=6 \cdot 6$ 〜30 mm 間でその他は外插した。すすなわち斯㧍よび切 線方间では中央が弓㖘，外周で生縮応力となり，赖方向 で $r=21 \sim 24 \mathrm{~mm}$ ，切線方向で. $r=15 \sim 18 \mathrm{~mm}$ にわい ては応力は zero となつている。応力除去の過程では応 力 zeroの点ははとんど変化なく，応力除去状況につい ては分布曲線のいずれか一简所についで調べればよい。

Fig. 3 は $r=10,20,30 \mathrm{~mm}$ に扔名各方间の応力 が加熱温度 ( 2 時間保持) 飞より除去される状沉を示す. 用いた 3 種の試料ではいずれも大差なく，ほぼ直線的な 际:去曲線をとり，各方咸の応力についてほぼ同一である。

2.ある加熱温度で保持時間を变えた場合

Table 1 亿示す陚料 8〜30，38〜49 はいずれも100 $\sim 600^{\circ} \mathrm{C}$ 加熱传当りその保持封間を变えたものである.

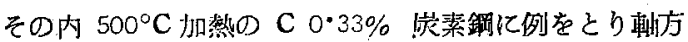
向の応力分布を Fig. 4 で示す. $700^{\circ} \mathrm{C}$ W.Q 試料比 し応力は非留に小となつているが，1１0 時間保持で若

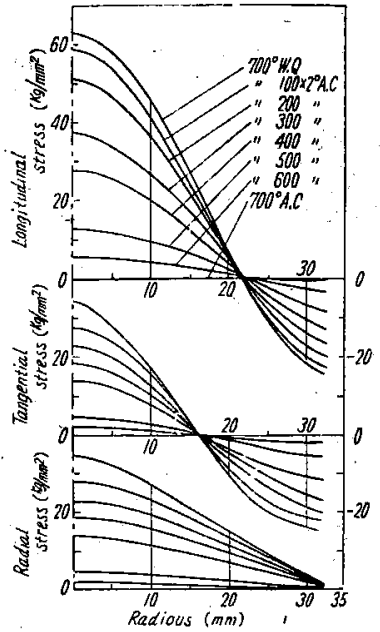

Fig. 2. Residual stress distribution in $70 \phi$ $\mathrm{r}$ ars heated $2 \mathrm{~h}$ at $100 \sim 600^{\circ} \mathrm{C}$.

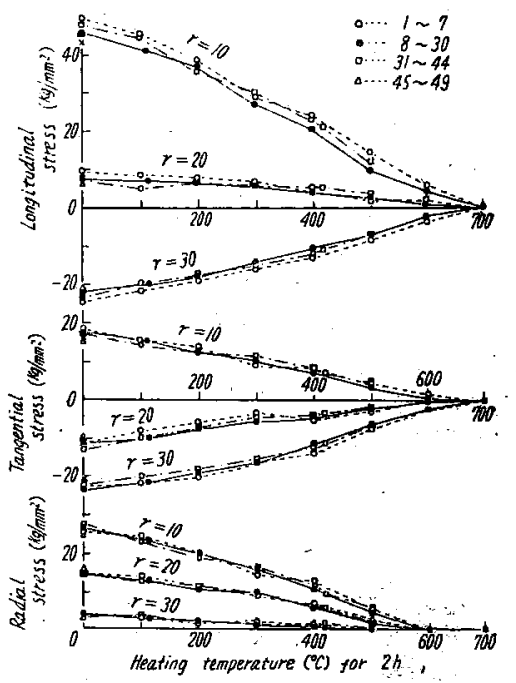

Fig. 3. Influence of heating temperatures on residual stress relieving at $r=10,20$, $30 \mathrm{~mm}$.

千変化する. Fig. 5 は $300^{\circ} \mathrm{C}, 500^{\circ} \mathrm{C}$ 保持の例を輣方 向応力について示したものである.すなわち加熱仁よ て応方除去が行われるが，䘞期の除去速度は大であるが 長㭙間加熱䎲よつては効果がほとんどない。てれはある 温度に加整される間に除去される量を含んでいるてとも

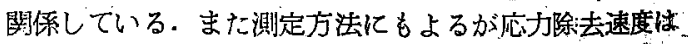
低温で小で高温になると非学に大となるととがかかる

3. 綜合的表示わよび硬度变化について 


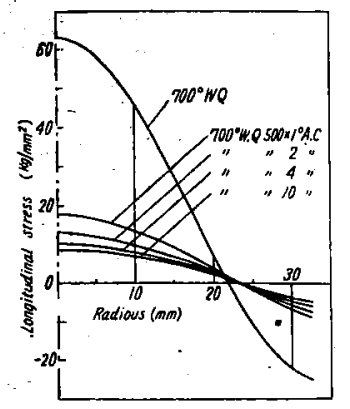

Fig. 4. Lnogitudinal stress distribution in $70 \phi$ bars heated $1 \sim 10 \mathrm{~h}$ at $500^{\circ} \mathrm{C}$.

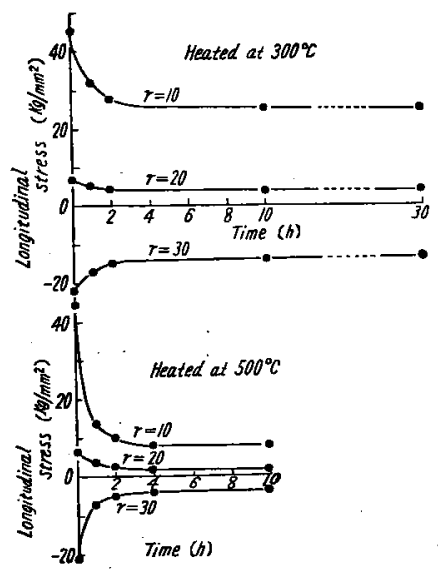

Fig. 5. Influence of heating time at $300^{\circ}$ and $500^{\circ} \mathrm{C}$ on the residual stress at $\boldsymbol{r}=10,20,30 \mathrm{~mm}$.

$r=10 \mathrm{~mm}$ 亿わける軸方向の応力について加熱温度わ よび時間の影響を取緾めたものが Fig. 6である.応力 除去恃大部分加熱温度の函数であつて保持時間敃ていて は余り影響を受けないとと，また高温加熱程除去速度が 大であるととがわかる。

Fig. 7 は希加熱温度で長時間保持した後(約 20 時間) の残留応力状況を示す. 各 2 時間保持した Fig. 3 と比 較して応力はさらに除去されているてとがわかる。ま た， $610^{\circ} \mathrm{C}$ 附近を zero とした直線関係がくわかる. こてで。 $\sigma_{0}$ を最初の残留応力とし，ある加熱温度 0 で長 時間加熱したときの残留応力を $\sigma_{1}$ とすると

$$
\sigma_{1} \fallingdotseq \sigma_{0}-\sigma_{0} \cdot \theta / 610(t \rightarrow \infty)
$$

\section{で簡単侸示される.}

Fig. 8 はこれら試料の表面硬度の变化を調べたもの で点線で示す曲線屾备種温度で 2 時間保持, 実線で示す 曲線は保持時間による変化を示す. Fig. 3，Fig. 5等に 示す結果とよく一致した傾问を表わしている。

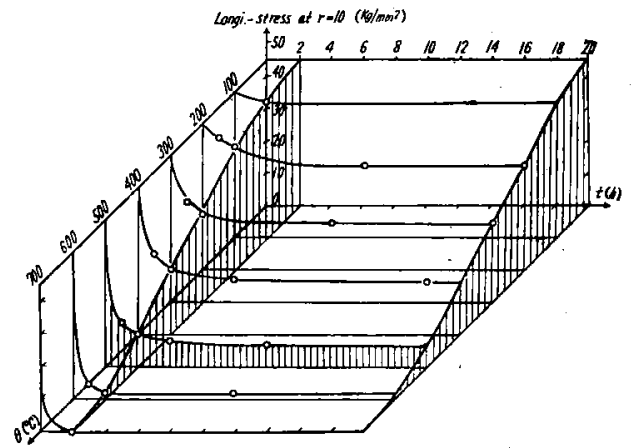

Fig. 6. Stress relieving diagram by heating temperatures and time.

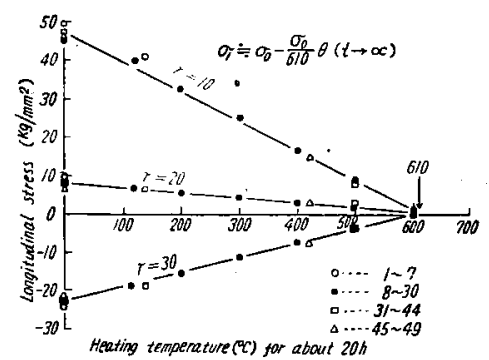

Fig. 7. Relation between residual stress and heating temperatures (after $20 \mathrm{~h}$ heating).

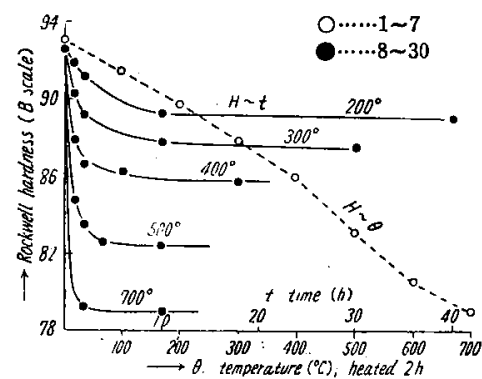

Fig. 8. Relation between surface hardness and heating temperatures and time.

\section{IV. 実験結果の考察}

残留応力除去は主として加熱温度 $\theta$ の函数で加熱時間 $t$ についてははとんど影疃は受けない: しかし Fig. 5, 6, 7 に示すごとく質量を考碱に入れてもなお若干応力 は時間によつて変化し，低温側では除去速度は小で高温 側で大である。ここで速度を考炼するには若干無理があ るが，光られた結果の表示に対して，つぎの考察を行 つた.

任意時間 $t$ 亿おける残留応力 $\sigma$ と長時間加熱 $(t \rightarrow \infty)$ 
によつてもなお除去しえさる応力 $\sigma_{1}$ との間に次式ので とき関係があると考えた。

$$
\frac{\partial}{\partial t}\left(\sigma-\sigma_{1}\right)=-\kappa\left(\sigma-\sigma_{1}\right)
$$

すなわち

とおいた， $\sigma_{1}$ を実測結果と合致するでとく たを適当に 遥ぶと Fig. 9 がえられる.ここでぇは応力除去速度恒 数之呼ぶべきもので, $\theta$ の函数である. かくして求めた ๔を日対して調べる Fig. 10 亿示すでとき直線開 係がえられる.すなわち

$$
\begin{array}{r}
\log _{e} \kappa+B / T=\log _{e} C=\text { const } \\
\kappa=c \cdot e^{-B / T} \ldots \ldots \ldots \ldots \ldots
\end{array}
$$

形式で表わざれる. $\boldsymbol{~}$ 力分布上で応力值の大なるものほどその傾斜が大きいが Bがての傾斜を表わす常数でてによつて定まるエネルギ 一量を示す． $C$ は $r$ 亿り定まる常数， $T$ は絶対温度 を示す。

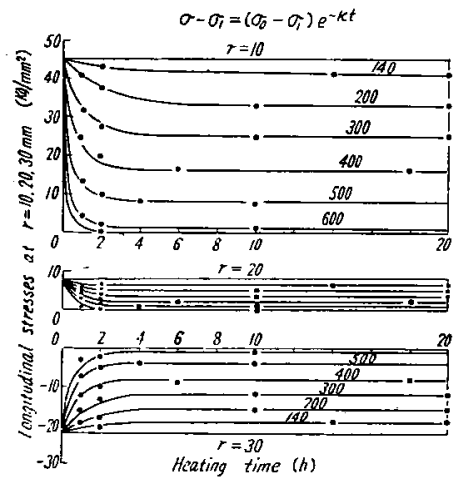

Fig. 9. Relation between residual stress and heating temperatures and time.

以上は残留応力除去については加熱温度, すなわち加 えた解除エネルギー量，によつて一定の除去量があり， さらに応力を除去するための長時間加熱けは意味がなく より大なる熱量を与克る必要があることを示した。また 加熱温度に比例した応力除去があり約 $610^{\circ} \mathrm{C}$ 附近で完 全に除去された。なお，ての実験結果と S. Fuchs'が $50 \phi の 0.30 \% \mathrm{C}$ の炭素銅を $850^{\circ} \mathrm{C}$ 汃ら水焼入れして

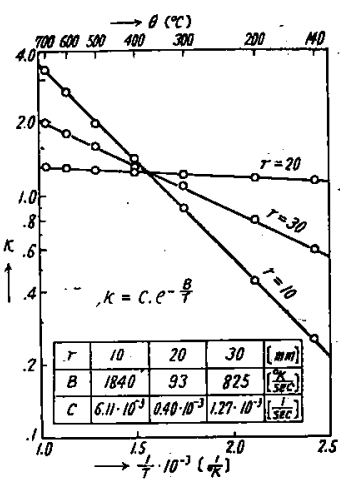

Fig. 10. Relation between the coef of stress relieving velocity and temperature.

各種温度に焼戻した時の残留応力測定結果と比較すると 変態による応力除去量ははとんどなく，急冷汇よる冾却 応力とその除去とが大部分を占めているととがかがる。

$$
\text { V. 結言 }
$$

70 中沈棒を $\mathrm{Ac}_{\mathbf{1}}$ 変態点直下から急冾した時の残留庥 力について，各種の温度時間で一様に加熱し，応力除去 状況を Sachs の方法で求めだ．その結果，加熱温度に よつて定まる一定の除去量があり，加熱庤間はほとんど 影留しない．また $610^{\circ} \mathrm{C}$ 附近ではほ完全に応力除去注 行われそれ以下では温度に比例して除去される.

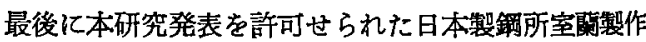

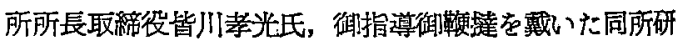
究部長下田秀夫搏士ならびに実験に並々ならぬ御尽力を 戴いた同研究部の大沢徳已君に深く感謝する。

（昭和 31 年 9 月笴稿）

$$
\text { 文. 献 }
$$

1) H. Bühler, E. Scheil: Arch. f. d. Eisenhüttenw. 6 (1933). 283, 7·(1933/34), 359

S. Fuchs: Arch. f. d. Eisenhüttenw, 7 $(1933 / 34), 315$

替野 猛: 本誌; 36 (1950), 61, 548

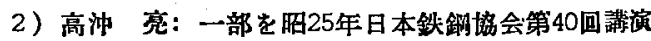
大会にて発表

3) G. Sachs: Z. f. Metallk. 19 (1927), 352 